\title{
A Wavelet-based Discussion on the Greek Stock Market Integration During the Last Decade
}

\author{
Boryana Bogdanova
}

Department of Statistics and Econometrics, Faculty of Economics and Business Administration, University of Sofia, 125 Tsarigradsko chausse blvd., Sofia, Bulgaria

\begin{abstract}
The current paper investigates how has been evolving the integration of the Greek stock market to the major world stock exchanges for a period spanning from the early 2000s till the middle of 2013. The idea of wavelet coherency is adopted in the analysis in order to identify linkages and co-movement patterns that are otherwise not that obvious. It is further investigated if the detected relationships are of short or of long-run character. Also particular attention is paid to the co-movement patterns during the period of the 2007-2009 financial crisis as well as during the period of the Eurozone debt crisis. In addition, conclusions on presence of contagion and transmission of crises are drawn.
\end{abstract}

Keywords: continuous wavelet transform, wavelet coherency, stock markets co-movement, financial contagion

\section{Introduction}

The issue of stock market integration and in particular the issue of stock market co-movement has been of great interest since the introduction of the portfolio theory. Before the beginning of the e-trade era it was a wide spread understanding that investments in different countries' securities are of crucial importance for the successful risk diversification. Even though during the last two decades the impact of risk diversification across industries has significantly increased, diversification across countries is still important [1]. On the other hand the issue of market comovement and in particular the issue of contagion became of special interest after the burst of the mortgage bubble followed by the Great Recession and the Eurozone debt crisis.

There are number of researches regarding the comovement of the developed stock markets [2]. Even though in the earlier researches there is some disagreement on whether the markets are becoming more integrated, in recent papers [3] it is shown that after the middle of 1990s the comovement between the markets of Germany, the USA, and the UK has significantly increased and only the market of Japan has been integrated to lesser extent. Also some recent research works [4] deal with the issue if stock markets from the South American, Asia-Pacific and the CEE regions are becoming more integrated with the world finances.

\footnotetext{
*E-mail address: bpelova@feb.uni-sofia.bg

ISSN: 1791-2377 @ 2015 Kavala Institute of Technology. All rights reserved.
}

However, the markets from Southeast Europe are still unexplored and the current paper contributes to the topic.

The research focus is set on the Greek stock market as it is of specific interest for the businesspeople, policymakers and academics. The current paper aims to provide a better understanding of the processes behind the Greek stock market integration under the influence of the last decade financial turbulences. It aims to find how the existing linkages have changed and these findings could be used as a starting point for decision-making, analysis and further research.

In particular, the current article investigates the comovement of the Greek stock market with the markets of Germany, Japan, the UK, and the USA. For the purpose of the analysis is utilized the continuous wavelet transform. This choice is determined by several factors. First of all, the wavelet transform is particularly useful tool in the analysis of financial data. As explained by Ramsey [5] the financial information is the output of decisions and actions taken by numerous economic agents operating simultaneously over different investment horizons. On the other hand, an inherent characteristic of the wavelet transform is its ability to represent any complicated data structure into simpler components characterized by a specific frequency. In fact the wavelet transform is especially well-suited to the analysis of stock market co-movements as the decomposition over different frequencies allows informational breakup across short- and long-run horizons. Another advantage of the utilized methodology is that the issue with the biasedness of estimates in times of turmoil is avoided and it might be seen that the most recent researches 
dealing with co-movement analysis [6] apply the wavelet approach.

Rest of the paper is structured as follows. In Section 2 is outlined the theoretical framework behind the utilized wavelet methodology. In Section 3 is presented the data and the major results, followed by a discussion. Section 4 concludes.

\section{Wavelet Coherency}

The conclusion on the degree of co-movement between two time series might be done on the basis of how strong their wavelet coherency is. For its calculation is utilized the continuous wavelet transform. A detailed discussion on the wavelet transform might be found for example in [7]. Rest of this section follows the presentation in [8].

A function $\psi(t) \in L^{2}(\mathbb{R}), L^{2}(\mathbb{R})$ denotes the set of square integrable functions, is said to be a mother wavelet if it satisfies the so called "admissibility condition" which is a decay condition and ensures that the function is well localized both in time and frequency. For functions with sufficient decay the admissibility condition is equivalent to requiring that

$\Psi(0)=\int_{-\infty}^{\infty} \psi(t) d t=0$,

where $\Psi(\omega)$ denotes the Fourier transform of $\psi(t)$. A family $\psi_{\tau, s}$ of wavelet daughters can be obtained by scaling and translating the mother wavelet $\psi$ :

$\psi_{\tau, s}=\frac{1}{\sqrt{|s|}} \psi\left(\frac{t-\tau}{s}\right), \quad s, \tau \in \mathbb{R}, s \neq 0$,

where $s$ is a scaling factor controlling the width of the wavelet and $\tau$ is a translation parameter controlling its location. Given a time series $x(t) \in L^{2}(\mathbb{R})$ its continuous wavelet transform with respect to the wavelt $\psi$ is defined as follows:

$W_{x ; \psi}(\tau, s)=\int_{-\infty}^{\infty} x(t) \frac{1}{\sqrt{|s|}} \psi^{*}\left(\frac{t-\tau}{s}\right) d t$

where the asterisk denotes complex conjugate. For simplicity of notation the wavelet transform $W_{x ; \psi}(\tau, s)$ will be denoted by $W_{x}$ in the text that follows. The cross-wavelet transform of two time series, $x(t)$ and $y(t)$, is given by Eq. (4):

$W_{x y}=W_{x} W_{y}^{*}$.

For the purpose of measuring co-movement it is suitable to utilize complex-valued wavelet and the most common choice is the Morlet wavelet which is utilized in the current paper as well.

The wavelet coherency of the time series $x(t)$ and $y(t)$ is denoted by $R_{x y}$ and is defined by Eq. (5):

$R_{x y}=\frac{\left|s\left(W_{x y}\right)\right|}{\left[S\left(\left|W_{x}\right|^{2}\right) s\left(\left|W_{y}\right|^{2}\right)\right]^{1 / 2}}$, where $S$ is a smoothing operator in both time and scale and $0 \leq R_{x y} \leq 1$. The closer the value of $R_{x y}$ to 1 , the stronger is the degree of synchronization between the time series $x(t)$ and $y(t)$, i.e. they are exhibiting stronger co-movement.

\section{Empirical Findings}

The raw data is downloaded from http://finance.yahoo.com/ and it consists of the closing prices of the stock indices presented in Tab. 1 for the period from 1-Jan-2002 to 1-Jul2013. For the purpose of the analysis is applied a monthly sampling rate as in this way is avoided the issue with different working hours and official holidays of the investigated stock exchanges. The closing prices are converted into monthly returns and the pairwise wavelet coherency defined by Eq. (5) is calculated. Its numerical realization is done through a freely available Matlab toolbox associated with the theoretical framework presented in the paper of Aguiar-Conraria and Soares [8]. The toolbox is available

http://sites.google.com/site/aguiarconraria/joanasoareswavelets.

Table 1. List of investigated stock indices.

\begin{tabular}{|c|c|}
\hline Index & Country \\
\hline $\begin{array}{l}\text { Athex Composite Share Price } \\
\text { Index }\end{array}$ & Greece \\
\hline DAX & Germany \\
\hline FTSE 100 & UK \\
\hline Nikkei 225 & Japan \\
\hline S\&P 500 & USA \\
\hline
\end{tabular}

The major results are presented as color maps due to the fact that calculation of wavelet coherency involves threedimensional representation. Each pixel of the map corresponds to a particular value of $R_{x y}$ and the color code is provided next to the maps. On Fig.1, panels (a) to (d), is presented the wavelet coherency of the return series of Athex Composite Share Price Index with the major indices of the USA, the UK, Germany and Japan respectively. For each of the panels the $\mathrm{x}$-axis corresponds to the time scale and the y-axis - to the frequency scale. For better understanding of the results, the frequencies are converted into time units where the finest scale corresponds to one month and the coarser scale - to five years. Additionally, the statistically significant coherencies are determined on the basis of Monte Carlo experiments and then they are contoured on the map. The cone of influence is plotted with tick black line and it represents the region in which the transform suffers from edge effects.

From Fig. 1(a) it might be seen that there is presence of significant co-movement between the return series of Athex Composite Share Price Index and S\&P 500 in the low frequency band (corresponding to 2-4 years) from the begging of the investigated period until 2010. This means that during this period there is presence of stock market integration related to the long-run investment horizons. An interesting finding is that during the period of the 2007-2009 financial crisis there is a strongly pronounced and at the same time stable increase in the co-movement over all frequencies. This is a clear indication of contagion [9], 
which means that the financial crisis in the USA was transmitted to Greek stock market.

However, the long-run relationship disappears soon after the beginning of the Greek sovereign debt crisis, which possibly means that the events in Greece do not affect the US stock market on a long-run basis. Still, until the end of 2011 there are some instances of short-term co-movements (1-4 months frequency band) which are of brief duration and might be interpreted as transient falls in the US stock market caused by announcements in the financial press for chances of negative influence of the Greek crisis on the US stock market. The latter two findings evidence that in spite of the

The latter finding might possibly mean that the UK stock market became less synchronized with the Greek market. This suggests that the events in Greece did not directly affect the UK stock market.

From Fig.1(c) it is might be seen an overall presence of co-movement between the German and the Greek stock market throughout the whole investigation period across most of the frequency bands. This indicates that there is presence of interdependence between the Greek and the German stock market which does not change considerably in times of turmoil. It should be noted that Forbes and Rigobon [10], adopt in their research a definition of contagion according to which it is defined as a significant increase in cross-market linkages after a shock to one country or a group of countries. On the other hand they outline that if the present co-movements do not increase significantly, then the high levels of co-movements are interdependence, but not a contagion. The latter facts provide grounding to believe that the Greek stock market is highly integrated to the Eurozone benchmark.

Fig. 1(d) provides evidence on presence of weak relationship between the Greek and the Japanese stock markets before the beginning of the 2007-2009 financial crisis. It is interesting to comment on the co-movement corresponding to the low frequency band which appeared after the beginning of the 2007-2009 financial crisis and continues until the end of the investigated period. A possible interpretation of such long-run horizon synchronization is that after the 2007-2009 crisis the government debt issue arose for both the economies of Greece and Japan. Even though it is paid less attention to Japan's sovereign debt, it might be seen from the figure that the Greek and the Japanese stock markets are sharing the same long-run path.

On Fig.2 are presented some of the pairwise wavelet coherencies between the returns of the major world stock indices in order to enable comparison and explain further some of the findings in this paper. From Fig.2(a) and Fig.2(b) it might be seen that the US mortgage crisis imposed a negative impact on the UK and the German stock markets through a well-established market interdependence. Comparing these results with Fig.1(a) it is more easily distinguished that Fig.1(a) indicates presence of financial contagion.

If Fig.1(c) is compared to Fig.2(d) it might be seen that even though the Greek stock market is well-integrated to the German market, the level of integration is not as strong as the UK - German stock market relationship.

Finally, Fig.2(c) indicates that there is presence of contagion from the US stock market to the Japanese market. But after the middle of 2010 there is no presence of long-run co-movement between the two markets. The latter fact is supportive to the hypothesis that the identified long-run relationship on Fig. 1(d) might be due to the sovereign debt issue. global fears there are no reasons to believe that the Geek debt crisis affected systematically the US stock market.

Analyzing Fig.1(b) one might say that there is significant co-movement between the Greek and the UK stock market across the low as well as across some of the high frequencies from the beginning of the investigated period until the beginning of the Greek debt crisis. This means that during this period the Greek stock market has been well integrated to the UK stock market. After that there is some decrease in co-movement across all of the frequency bands.
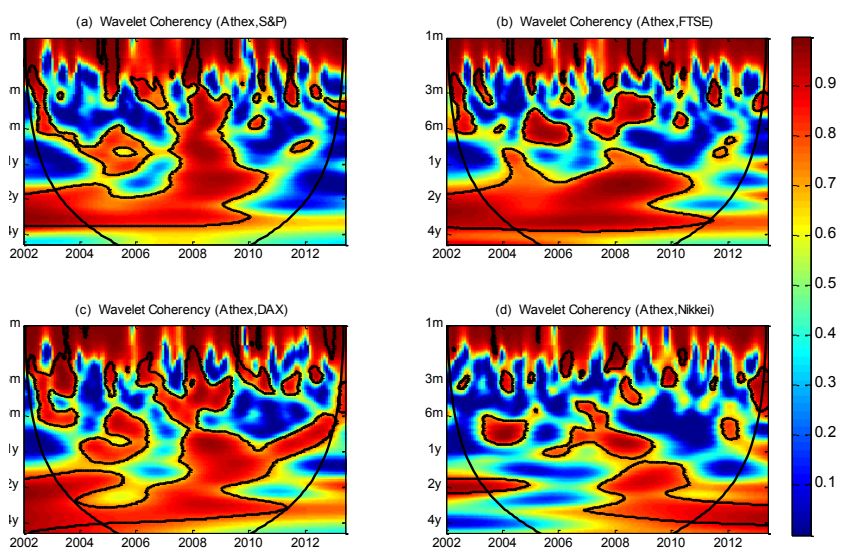

Fig. 1. Wavelet coherency of the return series of Athex Composite Share Price Index and S\&P 500 (a), Athex Composite Share Price Index and FTSE 100 (b), Athex Composite Share Price Index and DAX (c), Athex Composite Share Price Index and Nikkei 225 (d).
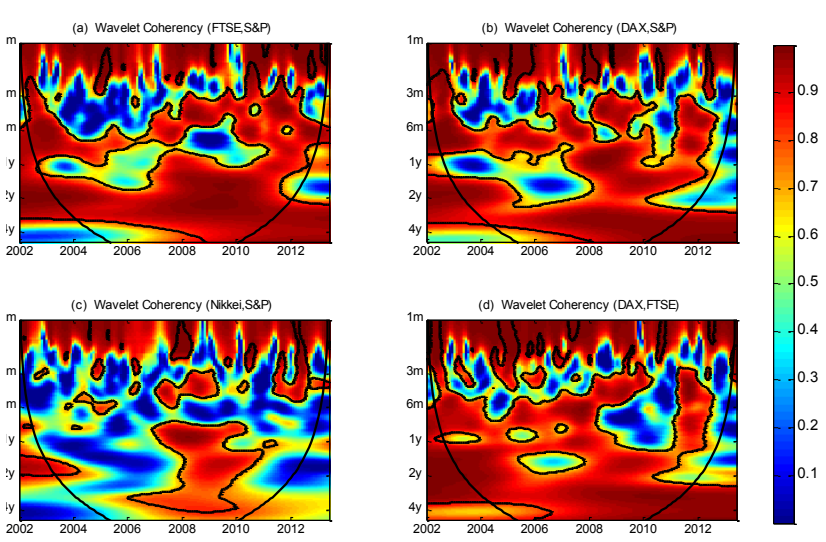

Fig. 2. Wavelet coherency of the return series of FTSE 100 and S\&P 500 (a), DAX and S\&P 500 (b), Nikkei and S\&P 500 (c), DAX and FTSE $100(d)$.

\section{Conclusion}

The current paper utilizes the continuous wavelet transform in order to investigate the Greek stock market integration during the last decade. The identified co-movement patterns evidence that the linkages between the Greek and the major world stock markets have went through certain changes during the recent times of turmoil. First of all, there is clear indication of contagion from the US to the Greek stock market after the burst of the mortgage bubble. However, soon after the beginning of the Greek debt crisis there is significant decrease in the US-Greek stock market comovement. Considering the relationship between the UK and the Greek stock market, it could be noted that the two 
markets are synchronized to a significant extent only until the beginning of the Greek debt crisis. On the other hand, the Greek stock market is well integrated to the German stock market throughout the whole investigation period and it seems that this integration did not changed significantly in times of turmoil. Finally, it could be concluded that the Japanese and the Greek stock market are sharing the same long-run path after the beginning of the Greek sovereign debt crisis. This finding might be interpreted as indication for the arising debt issue in Japan. The current paper conclusions could be used by investors and policymakers for decision-making as well as by scientists for further research work.

\section{Acknowledgements}

The author is thankful to Mr. Ivan Ivanov, Professor at the Department of Statistics and Econometrics, Sofia University, for the fruitful discussions and helpful comments which were of particular value to the current article.

\section{References}

[1]. R. Brooks and M. Del Negro, J.Empir.Financ. 11, 649 (2004).

[2]. The interested reader might find a review on the papers regarding the co-movement of developed stock markets for example in A. Rua, and L.C.Nunes, J.Empir.Financ. 16, 632 (2009).

[3]. A. Rua, and L.C.Nunes, J.Empir.Financ. 16, 632 (2009); M. Ranta, $\mathrm{PhD}$ thesis, Universitas Wasaenis (2010); L. Aguirar-Conraria and M.J.Soares, working paper, NIPE - Universidade do Minho (2011).

[4]. 4. B. Harrison, and W. Moore, Econ.Issues 15, 1 (2010); S. Ali, B.Z.Butt, and K.Rehman, World Appl.Sci. J. 12, 395 (2011); J.Barunik, L. Vacha, and L. Krištoufek, IES Working paper, Charles University Prague (2011); S.Dajcman, M.Festic, and A. Kavkler, Inz.Econ. 2322 (2012); J.Wang, J.Zhu, and F.Dou, China World Econ. 20, 102 (2012); L.Loh, Res.Int.Bus.Financ. 291 (2013).

[5]. J.Ramsey, Philos.T.Roy.Soc.A. 357, 2593 (1999).

[6]. S.Dajcman, M.Festic, and A. Kavkler, Inz.Econ. 2322 (2012); J.Wang, J.Zhu, and F.Dou, China World Econ. 20, 102 (2012);
L.Loh, Res.Int.Bus.Financ. 291 (2013); M.Madaleno and C.Pinho, Int.J. Finac.Econ. 17, 89 (2012).

[7]. R.Gençay, F.Selçuk, and B.Whitcher, An Introduction to Wavelets and Other Filtering Methods in Finance and Economics, Academic Press, New York (2001); D.B.Percival and A.T.Walden, Wavelet Methods for Time Series Analysis, Cambridge Press, Cambridge (2000); J. Ramsey, Stud.Nonlinear Dyn.E. 6 Article 1 (2002).

[8]. L. Aguirar-Conraria and M.J.Soares, working paper, NIPE Universidade do Minho (2011)

[9]. As argued in M. Ranta, PhD thesis, Universitas Wasaenis (2010), when the low frequency coherency exhibits stable behavior but at the same time there is an increase in the coherency corresponding to the higher frequencies, this is indicative for presence of contagion.

[10]. K.J.Forbes and R.Rigobon, J.Finance 57, 2223 (2002). 